\title{
Benzyl isothiocyanate and phenethyl isothiocyanate inhibit murine melanoma B16F10 cell migration and invasion in vitro
}

\author{
KUANG-CHI LAI ${ }^{1,2}$, YUNG-TING HSIAO ${ }^{3}$, JIUN-LONG YANG $^{4}$, YI-SHIH MA M, $^{5,}$, \\ YI-PING HUANG ${ }^{7}$, TAI-AN CHIANG ${ }^{1}$ and JING-GUNG $\mathrm{CHUNG}^{3,8^{*}}$
}

\author{
${ }^{1}$ Department of Medical Laboratory Science and Biotechnology, College of Medicine and Life Science, \\ Chung Hwa University of Medical Technology, Tainan; ${ }^{2}$ School of Medicine, China Medical University, \\ Taichung; Departments of ${ }^{3}$ Biological Science and Technology, ${ }^{4}$ Chinese Medicine Resources, \\ China Medical University, Taichung; ${ }^{5}$ School of Chinese Medicine for Post-Baccalaureate, I-Shou University, \\ Kaohsiung; ${ }^{6}$ Department of Chinese Medicine, E-Da Hospital, Kaohsiung; ${ }^{7}$ Department of Physiology, \\ China Medical University, Taichung; ${ }^{8}$ Department of Biotechnology, Asia University, Taichung, Taiwan, R.O.C.
}

Received May 18, 2017; Accepted July 17, 2017

DOI: 10.3892/ijo.2017.4084

\begin{abstract}
Benzyl isothiocyanate (BITC), and phenethyl isothiocyanate (PEITC) have been demonstrated to induce anticancer function in many human cancer cells and also inhibit cancer cell migration and invasion. However, there are no studies that show BITC and PEITC to inhibit cell migration and invasion in mouse melanoma B16F10 cells. In this study, we investigated anti-metastasis effects of BITC and PEITC in melanoma cancer cells in vitro. Under sub-lethal concentrations (from $1,2.5$ up to $5 \mu \mathrm{M}$ ), BITC and PEITC significantly inhibited cell mobility, migration and invasion nature of B16F10 cells. Gelatin zymography assay also showed that BITC and PEITC inhibited matrix metalloproteinase-2 (MMP-2) activity in B16F10 cells. PEITC reduced MAPK signaling associated proteins such as p-ERK1/2, p-p38 and p-JNK1/2 but BITC increased those MAPK signaling associated proteins. BITC and PEITC both suppressed the expression of RhoA, Ras, and SOS-1, however, PEITC increased FAK and GRB2 but BITC increased FAK at $48 \mathrm{~h}$. Furthermore, PEITC decreased the expression of MMP-2 and tissue inhibitors of matrix metalloproteinases (TIMP) but BITC increased them. PEITC
\end{abstract}

Correspondence to: Professor Jing-Gung Chung, Department of Biological Science and Technology, China Medical University, 91 Hsueh-Shih Road, Taichung 40402, Taiwan, R.O.C.

E-mail: jgchung@mail.cmu.edu.tw

Dr Yi-Shih Ma, School of Chinese Medicine for Post-Baccalaureate, I-Shou University, 8 Yida Road, Yanchao, Kaohsiung 82445, Taiwan, R.O.C.

E-mail:m2367591@ms25.hinet.net

*Contributed equally

Key words: benzyl isothiocyanate, phenethyl isothiocyanate, migration, invasion, NF- $\kappa \mathrm{B}, \mathrm{MMP}-2$ inhibited NF- $\kappa \mathrm{B}$ protein levels and DNA binding which was confirmed by electrophoretic mobility shift (EMSA) assay. Based on these observations, we suggest that BITC and PEITC can be used in anti-metastasis of melanoma cells in the future.

\section{Introduction}

Melanoma has been recognized to be one of the most malignant tumors with the most aggressive and treatment-resistant form of human skin cancer. Currently its incidence is still increasing worldwide. The treatment for this disease after it spread beyond the primary site is difficult (1). Melanoma has rapid proliferation rate (2), however, the exact mechanisms of the rapid proliferation of melanoma cells was unclear (3). Melanoma cell metastasis is also a cause for difficulty in curing this disease. Although melanoma treatment has shown some breakthroughs in targeted and immunotherapy (4), it is still urgently needed to identify new targets for melanoma treatment.

PEITC, a member of isothiocyanates (ITCs), have been shown to induce cell cycle arrest PC-3 human prostate cancer cells (5), oral cancer cells (6), gastric cancer cells (7) and gastric cancer cells (8). Furthermore, several studies have shown that PEITC induced human cancer cell apoptosis (9-11) and it also inhibited nuclear factor $-\kappa \mathrm{B}(\mathrm{NF}-\kappa \mathrm{B})$-regulated gene expression (12) and activation of Atg5-mediated autophagy (13) in human prostate cancer cells. PEITC is also used in clinical trials for lung cancer (14). It was reported that PEITC inhibits the invasion of EGF-stimulated SAS oral cancer cells via targeting EGFR and also to induce its downstream signaling molecules for reducing the expression and enzymatic activities of both matrix metalloproteinase-2 (MMP-2) and MMP-9 (15).

BITC, also one of ITCs, has been shown to induce cell apoptosis in many human cancer cell lines such as bladder cancer cells (16), breast cancer cells (17), ovary cancer cells (18), prostate cancer cells (19) and melanoma A375.S2 cells (20). Furthermore, BITC induced cell cycle arrest and 
apoptosis in human leukemia cells through the downregulation of myeloid cell leukemia-1 (Mcl-1) (21) and alters the gene expression with cell cycle regulation and cell death in human brain glioblastoma GBM 8401 cells (22).

Metastasis, a multistep process, which is often resistant to conventional therapies such as chemotherapy and radiation therapy, is involved in cell motility, cellular adhesion and invasiveness, entry to blood circulation, and stays in other tissues for new colonization of a distant site (23). One of the major steps for cancer cell metastasis is the breakdown of connective tissue barriers which is involved with proteolytic enzymes such as MMPs to mediate ECM breakdown and facilitate invasion (24). ITCs inhibit the invasion and migration via blocking FAK/JNK-mediated MMP-9 expression in mouse C6 glioma cells (25). In lung cancer cells, BITC and PEITC inhibit cell metastasis potential via the modulation of metastasis-related gene expression and the inhibition of Akt/ $\mathrm{NF}-\kappa \mathrm{B}$ pathway (26). However, there is no available report to show BITC and PEITC suppressing the migration and invasion of mouse melanoma cells. Thus, we investigated the effects of BITC and PEITC on the B16F10 cell metastasis and we found that BITC and PEITC suppressed the migration and invasion of B16F10 cells in vitro.

\section{Materials and methods}

Test compound, reagents and culture medium. Benzyl isothiocyanate (BITC), phenethyl isothiocyanate (PEITC), dimethyl sulfoxide (DMSO), propidium iodide (PI), Tris-HCl, Trypsin and Trypan blue were purchased from Sigma Chemical Co. (St. Louis, MO, USA). BITC and PEITC were dissolved in DMSO as a carrier solvent and control cultures $0.5 \%$ DMSO. DMEM medium, fetal bovine serum (FBS) and penicillinstreptomycin were purchased from Invitrogen (Carlsbad, CA, USA).

Cell culture. Murine melanoma B16F10 cell line was obtained from the Food Industry Research and Development Institute (Hsinchu, Taiwan). Cells were cultured in $75 \mathrm{~cm}^{2}$ flask with DMEM supplemented with $10 \%$ FBS, $100 \mathrm{U} / \mathrm{ml}$ penicillin and $100 \mu \mathrm{g} / \mathrm{ml}$ streptomycin in $5 \% \mathrm{CO}_{2}$ humidified incubators at $37^{\circ} \mathrm{C}$.

Cell viability assay. B16F10 cells $\left(1 \times 10^{5}\right.$ cells/well) were maintained in 12-well plates with DMEM for $48 \mathrm{~h}$ and then PEITC were added to cells at final concentrations $(0,1,2.5,5$, 10 and $15 \mu \mathrm{M})$ and BITC were added to cells at final concentrations $(0,1,2.5,5$ and $10 \mu \mathrm{M})$ for $48 \mathrm{~h}$. After incubation, cells were collected from each treatment, washed with PBS and were stained with PI $(5 \mu \mathrm{g} / \mathrm{ml})$. All samples were analyzed by flow cytometry (Becton-Dickinson, San Jose, CA, USA) for percentage of viable cells as previously described (27).

Scratch wound healing assay. To investigate the wound healing effect of PEITC and BITC on murine melanoma cells, B16F10 cells ( $2 \times 10^{5}$ cells/well) were placed in 6-well plate for $24 \mathrm{~h}$ and after the cells formed a confluent monolayer, they were scratched using a sterile pipette tip to create a wound at confluence and washed in PBS to remove cell debris. Cells in each well were incubated with PEITC and BITC at the final concentrations $(0,1,2.5$ and $5 \mu \mathrm{M})$ at $37^{\circ} \mathrm{C}$ with $5 \% \mathrm{CO}_{2}$ at time $=0$ and $24 \mathrm{~h}$ and were photographed by phase contrast microscopy. The relative wound size at each time point of treatment was quantified by ImageJ software. Cell migration inhibition rate $(\%)=$ new scratch width/original scratch width $\mathrm{x} 100 \%$ as previously described $(28,29)$.

Cell migration and invasion assay. Matrigel Cell Migration Assay and Invasion System were used for measuring cell migration and invasion in vitro as previously described (30). Cell migration was performed with Transwell cell culture chambers (8-mm pore size; Millipore, Temecula, CA, USA). B16F10 cells $\left(5 \times 10^{4}\right.$ cells/well) were added in serum-free DMEM and were placed in the upper chamber which was coated with collagen of the Transwell insert and incubated with PEITC and BITC $(0,1,2.5$ and $5 \mu \mathrm{M})$. DMEM with $10 \%$ FBS was placed in the lower chamber and were incubated for $48 \mathrm{~h}$. The invasive cells (penetrated the filter in the lower surface) were fixed with $4 \%$ formaldehyde in PBS and stained with $2 \%$ crystal violet and were examined and photographed under light microscopy at $\mathrm{x} 200$ followed by counting for the percentage of inhibition (30). Cell invasion experiment was performed similarly to cell migration assay, using matrigel collagen to replace collagen on the filter membrane (30).

Gelatin zymography assay. B16F10 cells (5x10 cells/well) were maintained in 6-well culture plates for approximately $80 \%$ confluency. The serum-free medium with PEITC or BITC was added to each dish for $24 \mathrm{~h}$ culture. After incubation, the conditioned medium was collected from each treatment for measuring the total proteins; a $50 \mu \mathrm{g}$ of protein from each treatment was electrophoresis on 10\% SDS-PAGE containing $0.2 \%$ gelatin. Gel was washed and soaked in $2.5 \%$ Triton $\mathrm{X}-100$ in $\mathrm{dH}_{2} \mathrm{O}$ twice at $25^{\circ} \mathrm{C}$ for 30 min twice. Gels were soaked in substrate buffer $\left(50 \mathrm{mM}\right.$ Tris $\mathrm{HCl}, 5 \mathrm{mM} \mathrm{CaCl}_{2}$, $0.02 \% \mathrm{NaN}_{3}$ and $1 \%$ Triton $\mathrm{X}-100, \mathrm{pH}$ 8.0) while shaking for $18 \mathrm{~h}$ at $37^{\circ} \mathrm{C}$. Gels were stained with $0.2 \%$ Coomassie blue (Bio-Rad, Hercules, CA, USA) in 10\% acetic acid and $50 \%$ methanol $(30,31)$ and were photographed on a light box. Proteolysis was detected as a white zone (MMP-2 gelatinolytic activities) in a dark blue field.

Protein extraction and western blot analysis. B16F10 cells $\left(1 \times 10^{6}\right.$ cells) in $10-\mathrm{cm}$ dish were incubated with PEITC or $\operatorname{BITC}(0,1,2.5$ and $5 \mu \mathrm{M})$ for 24 and $48 \mathrm{~h}$. After incubation, cells were collected and lysed in ice-cold potassium phosphate buffer (pH 7.4) containing 2 mM EDTA and $0.1 \%$ Triton X-100 for sonication and centrifuged and total protein was measured by Bio-Rad protein assay kit (Bio-Rad) with bovine serum albumin (BSA) as the standard as previously described (30). The protein from each treatment of total cells was separated by $12 \%$ SDS-polyacrylamide gel electrophoresis, and transferred onto PVDF nitrocellulose membrane (Millipore, Bedford, MA, USA). The membrane was blocked with $5 \%$ non-fat milk in TBS-T buffer $(10 \mathrm{mmol} / \mathrm{l}$ Tris- $\mathrm{HCl}, 150 \mathrm{mmol} / \mathrm{l} \mathrm{NaCl}$, and $0.05 \%$ Tween-20, $\mathrm{pH} 7.8$ ) at room temperature fort $1 \mathrm{~h}$ followed by washing in TBS-T buffer. The membrane was incubated with monoclonal antibodies such as anti-p-ERK1/2, anti-p-p38, anti-p-JNK1/2, anti-PKC, anti-phosphatidylinositol 3 kinase (PI3K), anti-p-AKT (Thr308), anti-p-AKT(Ser473), anti-PCAN 

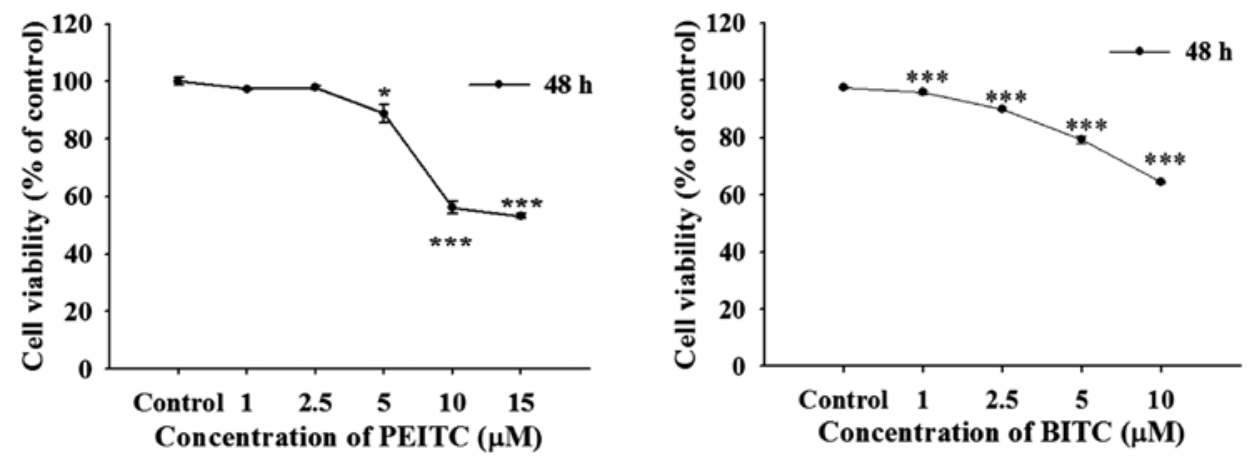

Figure 1. PEITC and BITC affect the cell viability. B16F10 cells $\left(1 \times 10^{5}\right.$ cells/well) were treated with various concentrations $(0,1,2.5,5,10$ and $15 \mu \mathrm{M})$ of PEITC and BITC for $48 \mathrm{~h}$. Cells were harvested for total cell viability as described in Materials and methods. ${ }^{*} \mathrm{P}<0.05,{ }^{* * *} \mathrm{P}<0.001$ significant difference between PEITC- and BITC-treated groups and the control as analyzed by Student's t-test.
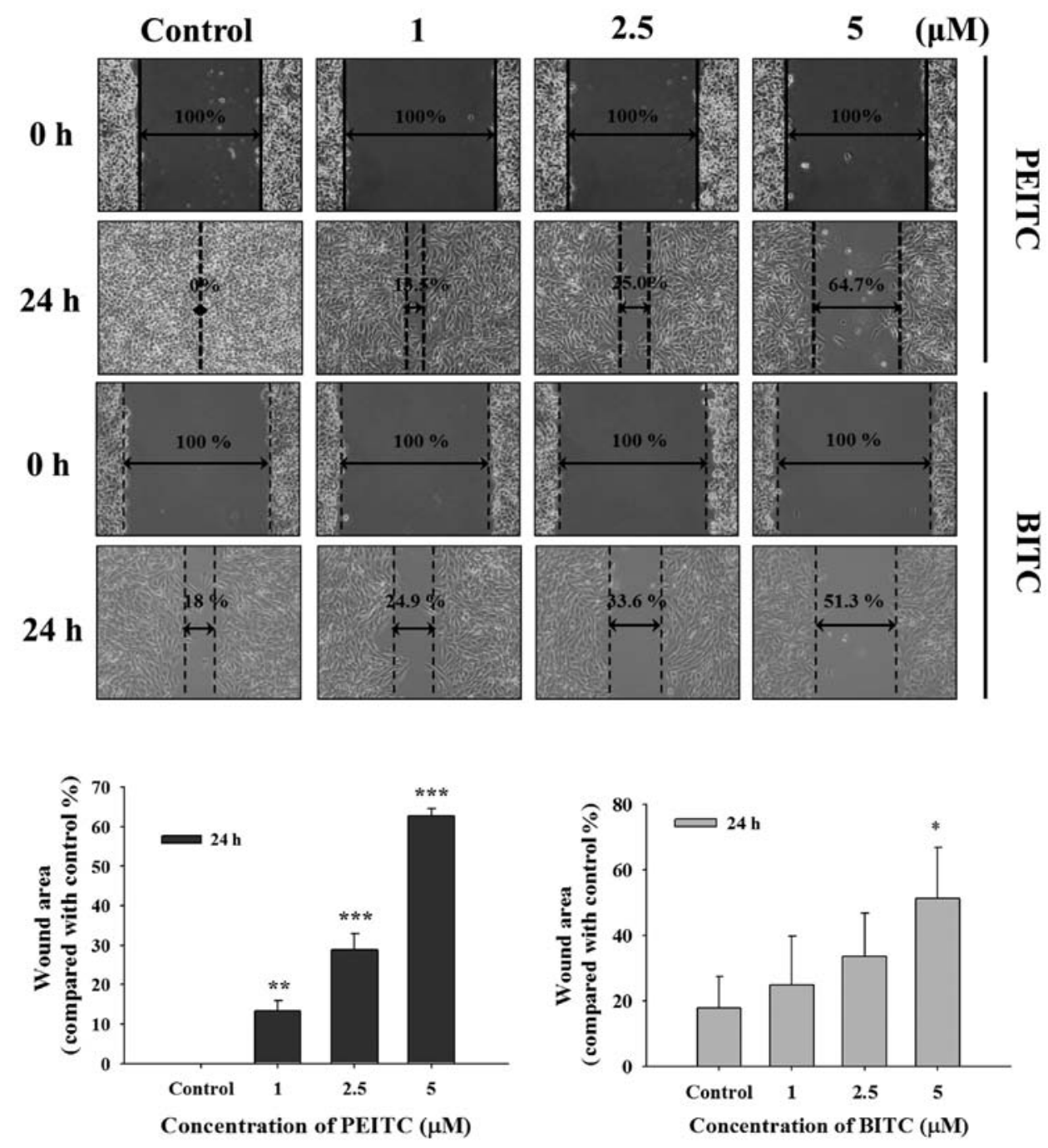

Figure 2. PEITC and BITC affect in vitro wound closure of B16F10 cells. Cells $\left(2 \times 10^{5}\right.$ cells/well) were placed in a 6 -well plate for $24 \mathrm{~h}$ and were wounded with a scratch and rinsed to remove debris and then were incubated with or without PEITC and BITC $(0,1,2.5$ and $5 \mu \mathrm{M})$ for $24 \mathrm{~h}$. The relative wound closures were monitored and photographed using phase contrast microscopy. The percentage of inhibition was calculated.

anti-p-FAK, anti-RhoA, anti-Ras, anti-GRB2, anti-SOS-1, antiMMP-2, anti-MMP-9, anti-uPA, anti-TIMP-1, anti-NF-kBp65, anti-NF-kBp50 and anti-E-cadherin. Membranes were washed and incubated with the diluted secondary antibodies (goat antimouse immunoglobulin G (IgG), diluted 1:5000, Santa Cruz
Biotechnology Inc., Dallas, TX, USA; goat anti-rabbit IgG, diluted, 1:5,000, Santa Cruz Biotechnology Inc.).

Investigated proteins on the membrane were visualized using the enhanced chemiluminescence detection system $\left(\mathrm{ECL}^{\circledR}\right.$, Millipore, Temecula, CA, USA) $(30,32)$. 
A

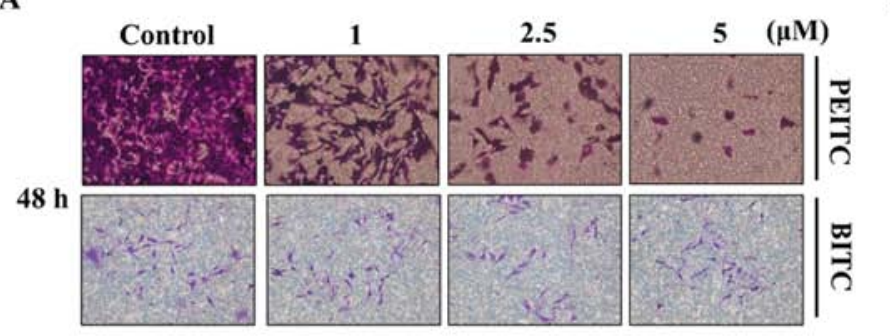

B

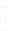
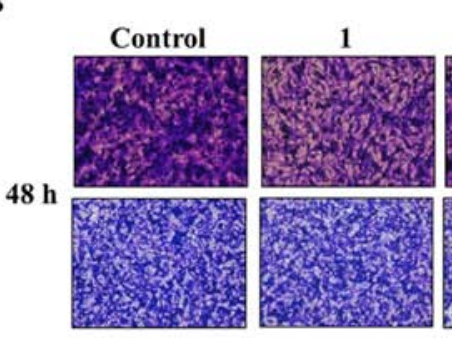
2.5

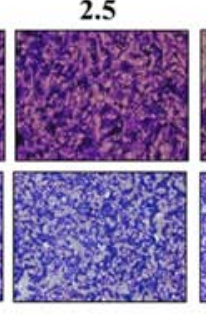

$5 \quad(\mu \mathrm{M})$

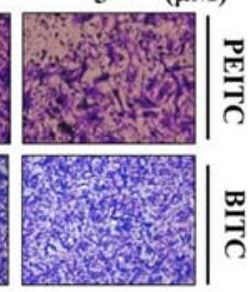

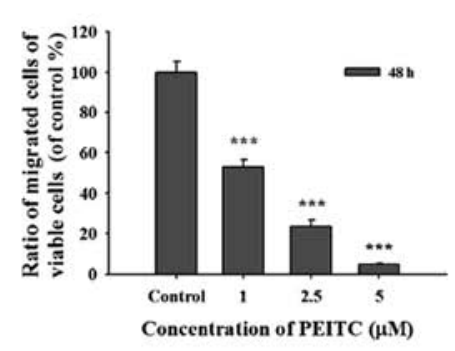
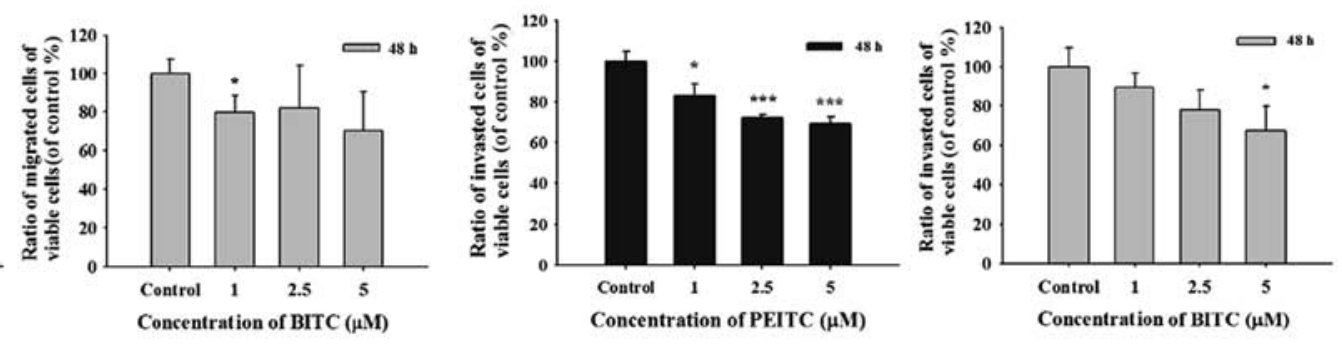

Figure 3. PEITC and BITC suppressed the migration and invasion of B16F10 cells in vitro. Cells (5x104 cells/well) were placed on a filter coated with collagen for migration or Matrigel for invasion and were treated with various concentrations $(0,1,2.5$ and $5 \mu \mathrm{M})$ of PEITC and BITC for $48 \mathrm{~h}$. B16F10 cells penetrated through to the lower surface of the filter and were stained with crystal violet and were photographed under a light microscope at $\mathrm{x} 200$ (A and B) and cells were counted (A and B) as described in Materials and methods. Results are from three independent experiments. ${ }^{*} \mathrm{P}<0.05$, ${ }^{* * *} \mathrm{P}<0.001$, significant difference between PEITC- and BITC-treated groups and the control as analyzed by Student's t-test.

Electrophoretic mobility shift assay(EMSA). A 5x105 cells/well of B16F10 cells were placed in a 12-well and were treated with $0,1,2.5$ and $5 \mu \mathrm{M}$ of PEITC and BITC for $48 \mathrm{~h}$. Cells were collected for nuclear extracts by the NE-PER Nuclear and Cytoplasmic Extraction kit (Pierce, Rockford, IL, USA). Nuclear extract protein $(5 \mu \mathrm{g})$ was performed for EMSA with a LightShift Chemiluminescent EMSA kit (Pierce) according to the manufacturer's protocol. 5'-Biotin-GATCCAGGGG ACTTTCCCTAGC-3' (biotin end-labeled oligonucleotide sequences) corresponding to the consensus of $\mathrm{NF}-\kappa \mathrm{B}$ was developed as previously described (33). Both biotin endlabeled duplex DNA were then incubated with a nuclear extract for further electrophoresis in $6 \%$ polyacrylamide native gel and then a 100-fold excess of unlabeled double stranded oligonucleotide was added to the reaction for competition. Both samples (DNA) were transferred to a positive nylon membrane. They were UV cross-linked and probed with biotin-HRP conjugate for incubating with the substrate of ECL kit (Millipore) as previously described (33).

Statistical analysis. All data represent at least 3 independent experiments and are expressed as mean \pm SD. A significant difference between the PEITC and BITC-treated and control groups were compared by Student's t-test. " $\mathrm{P}<0.05$ and ${ }^{* * * *} \mathrm{P}<0.001$ were considered as an indication of statistical significance.

\section{Results}

PEITC and BITC decrease the viability of B16F10 cells. In order to understand the possible concentrations for inhibiting cell migration and invasion of B16F10 cells, cells were incubated with PEITC $(0-15 \mu \mathrm{M})$ and BITC $(0-10 \mu \mathrm{M})$ for $48 \mathrm{~h}$. After incubation, cells from each treatment were collected for measuring cell viability by flow cytometric assay and results

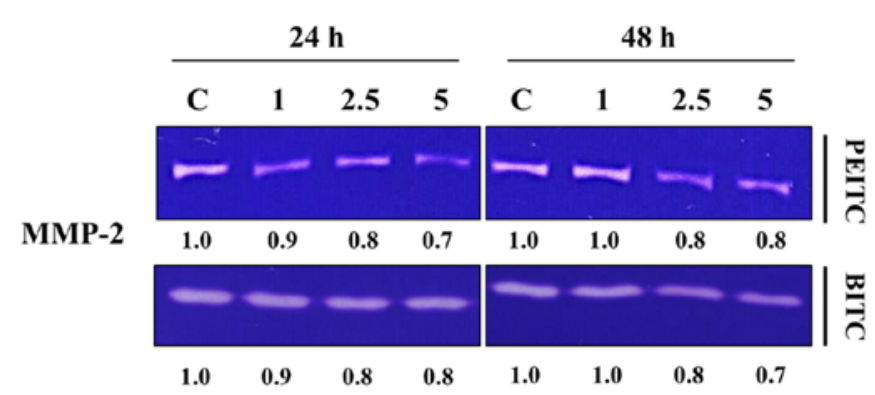

Figure 4. PEITC and BITC affect the activities of MMP-2 in B16F10 cells. Cells $\left(5 \times 10^{4}\right.$ cells/well) were incubated with $0,1,2.5$ and $5 \mu \mathrm{M}$ of PEITC and BITC for 24 and $48 \mathrm{~h}$ and then conditioned medium was collected and gelatin zymography assay was performed as described in Materials and methods. The different activity of MMP-2 was determined by ImageJ software and the results are expressed as a percentage of the control (100\%).

are shown in Fig. 1. Results indicated that PEITC and BITC significantly reduced total cell viability from 5 to $15 \mu \mathrm{M}$ and 1 to $10 \mu \mathrm{M}$, respectively in B16F10 cells. Therefore, we selected $1,2.5$, and $5 \mu \mathrm{M}$ for scratch wound healing assay, cell migration and invasion experiments.

PEITC and BITC inhibit cell mobility in B16F10 cells. Scratch wound healing assay was used to investigate the inhibition of PEITC and BITC on cell mobility of B16F10 cells in vitro and results are shown in Fig. 2. One of the representative figures was present and wound healing images (cell mobile capabilities) were undertaken at the same magnification and time (0 and $24 \mathrm{~h})$ after PEITC and BITC treatments in B16F10 cells. PEITC and BITC decreased the closure rate of the scratch, dose-dependently, when compared to the control group at $24 \mathrm{~h}$ treatment. Based on the results, it indicated that BITC at $1-2.5 \mu \mathrm{M}$ has higher inhibition of cell mobility than that of PEITC (Fig. 2). 
A

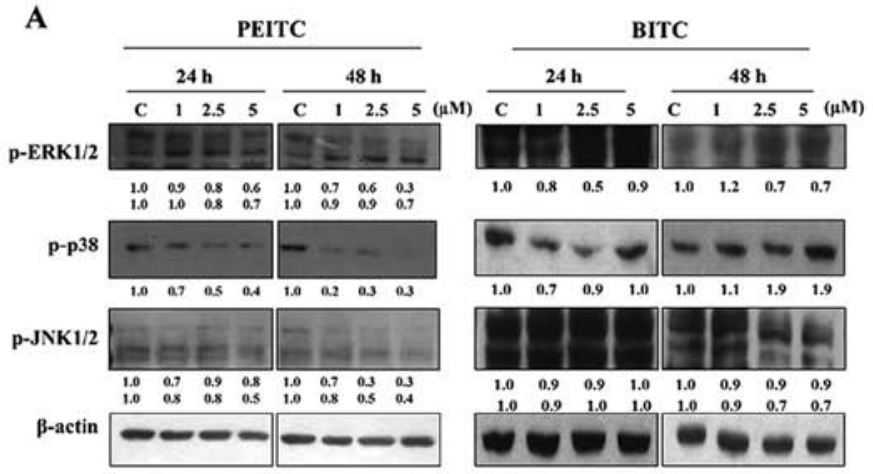

C

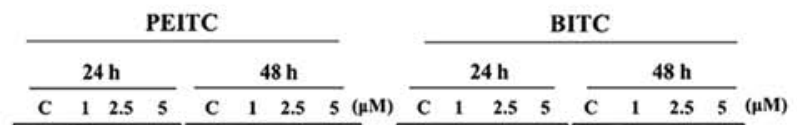

GRB2 $\infty=-\infty-\infty$

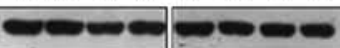

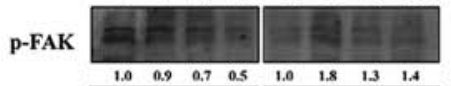

Rho A

$\begin{array}{llllllll}1.0 & 0.9 & 0.7 & 0.5 & 1.0 & 1.8 & 1.3 & 1.4\end{array}$ $\begin{array}{llllllll}1.0 & 0.6 & 0.5 & 0.4 & 1.0 & 1.0 & 0.6 & 0.5\end{array}$

Ras

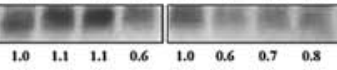

$\begin{array}{llllllll}1.0 & 1.0 & 0.9 & 1.0 & 1.0 & 1.2 & 1.2 & 1.4\end{array}$

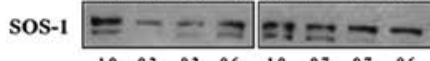

\begin{tabular}{llllllll}
1.0 & 0.2 & 0.2 & 0.6 & 1.0 & 0.7 & 0.7 & 0.6 \\
\hline
\end{tabular}

B-actin

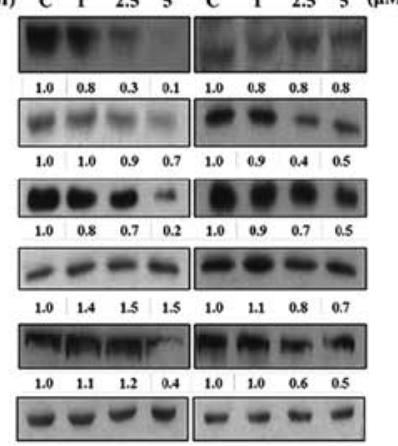

$\mathbf{E}$
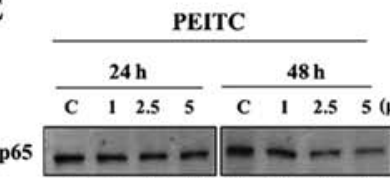

\begin{tabular}{lllllllll}
\hline 1.0 & 1.0 & 1.0 & 0.9 & 1.0 & 0.8 & 0.6 & 0.5
\end{tabular}

p50

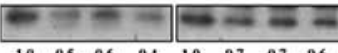

$\begin{array}{lllllllll}1.0 & 0.5 & 0.6 & 0.4 & 1.0 & 0.7 & 0.7 & 0.6\end{array}$

$\beta$-actin
B
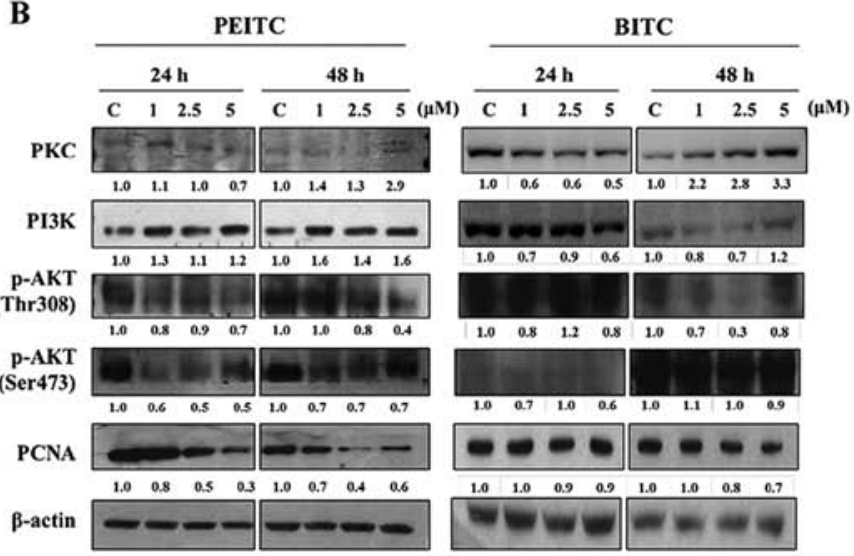

D

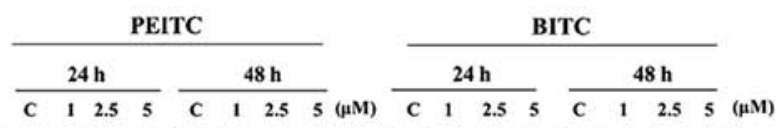

MMP-2

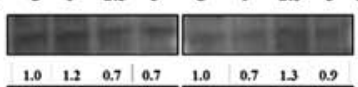

\begin{tabular}{lllllllll}
1.0 & 0.8 & 0.6 & 0.6 & 1.0 & 0.5 & 0.2 & 0.0 \\
\hline
\end{tabular}
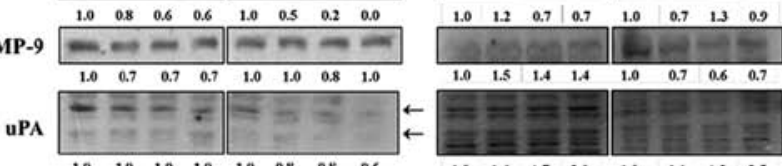

$\begin{array}{llllllll}1.0 & 1.0 & 1.0 & 1.0 & 1.0 & 0.8 & 0.8 & 0.6 \\ 1.0 & 1.5 & 1.7 & 2.3 & 1.0 & 1.0 & 1.0 & 1.0\end{array}$

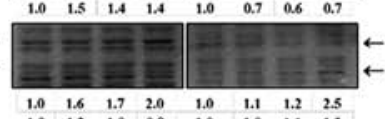

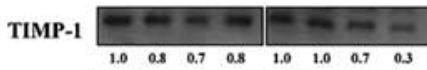
$\begin{array}{llllllll}1.0 & 1.6 & 1.7 & 2.0 & 1.0 & 1.1 & 1.2 & 2.5 \\ 1.0 & 1.2 & 1.0 & 0.8 & 1.0 & 1.0 & 1.1 & 1.3\end{array}$

B-actin $\longrightarrow-\infty$

Figure 5. PEITC and BITC affect the levels of associated proteins in migration and invasion of B16F10 cells. Cells (1x10 6 cells/dish) were treated with PEITC and BITC $(0,1,2.5$ and $5 \mu \mathrm{M})$ for 24 and $48 \mathrm{~h}$. Cells were collected and total protein was determined and for SDS page gel electrophoresis as described in the Materials and methods. The levels of p-ERK1/2, p-p38 and p-JNK1/2 (A), PKC, PI3K, p-AKT (Thr308), p-AKT (Ser473) and PCNA (B), p-FAK, RhoA, Ras, GRB2 and SOS-1 (C), MMP-2, MMP-9, uPA and TIMP-1 (D), NF- $\kappa$ Bp65 and NF- $\kappa$ Bp50 (E) and E-cadherin (F) expression levels were estimated by western blotting as described in Materials and methods.

PEITC and BITC suppress migration and invasion of B16F10 cells. In order to further investigate PEITC and BITC suppressed cell migration and invasion in B16F10 cells, the Transwell chamber coated with collagen for cell migration and coated with matrigel for cell invasion were performed and the results are shown in Fig. 3. Fig. 3A indicated that PEITC (1-5 $\mu \mathrm{M})$ significantly suppressed the migration of B16F10 cells dose-dependently; however, BITC only at $1 \mu \mathrm{M}$ induced the inhibition of cell migration. PEITC suppressed cell migration was greater than that of BITC. Fig. 3B indicated that PEITC (1-5 $\mu \mathrm{M})$ significantly suppressed the invasion of B16F10 cells dose-dependently; however, BITC only at $5 \mu \mathrm{M}$ induced the inhibition of cell invasion. PEITC suppressed cell invasion was greater than that of BITC.
PEITC and BITC inhibit MMP-2 activities in B16F10 cells. B16F10 cells were incubated with various concentrations of PEITC and BITC for 24 and $48 \mathrm{~h}$ and were collected for MMP-2 activities by using the gelatin zymography assay and the results are shown in Fig. 4. Results indicated that PEITC and BITC suppressed the activities of MMP-2 in B16F10 cells. The inhibition rate between PEITC and BITC are not significantly different; however both compounds are significantly different when compared to control groups.

PEITC and BITC affect key metastasis-related proteins in B16F10 cells. For further investigating PEITC and BITC suppressed cell invasion and migration involved in the inhibition of metastasis-associated protein expression in B16F10 


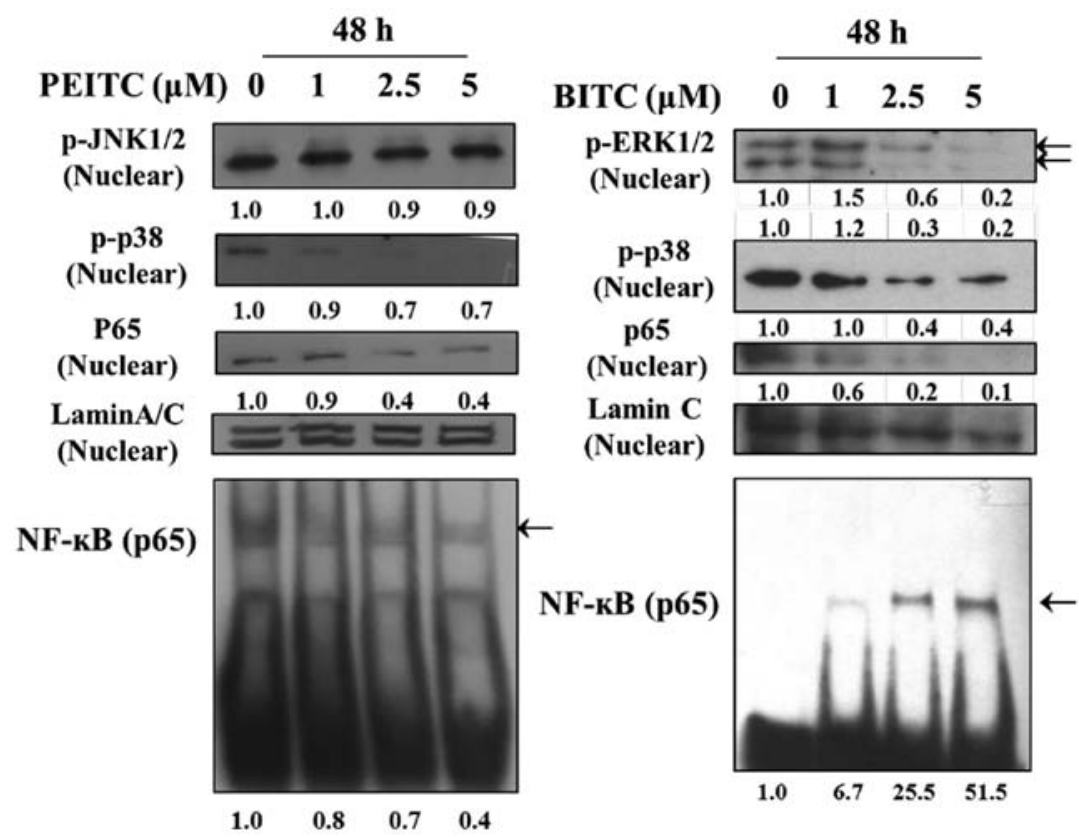

Figure 6. PEITC and BITC affect the binding of NF-kBp65 on DNA in B16F10 cells. For further confirming the effects of PEITC and BITC on the binding of NF- $\mathrm{kBp} 65$ on DNA in B16F10 cells, cells were treated with PEITC and BITC $(0,1,2.5$ and $5 \mu \mathrm{M})$ for $48 \mathrm{~h}$ and then were assayed by using EMSA as described in Materials and methods.

cells, cells after incubation with PEITC and BITC $(0,1,2.5$ and $5 \mu \mathrm{M}$ ) for 24 and $48 \mathrm{~h}$ were harvested for western blotting and the results are shown in Fig. 5. The results revealed several depressed key metastasis-related proteins, such as p-ERK1/2, P-p38 and p-JNK1/2 underwent significant reduction at 24 and $48 \mathrm{~h}$ treatment by PEITC (Fig. 5A). However, BITC treatment occurred at both time periods and only p-ERK1/2 was significantly reduced (Fig. 5A). At PEITC and BITC treatment at 24 and $48 \mathrm{~h}$, the p-AKT (Thr308), p-AKT (Ser473) and PCNA were significantly reduced when compared to control, however, PKC and PI3K were significantly increased when compared to control in PEITC treatment, and PKC and PI3K were reduced at $24 \mathrm{~h}$ treatment of BITC but it increased the expression of PKC and PI3K at $48 \mathrm{~h}$ treatment of BITC (Fig. 5B). The RhoA, Ras and SOS-1 were reduced at 24 and $48 \mathrm{~h}$ treatment of PEITC, p-FAK was reduced at $24 \mathrm{~h}$ treatment of PEITC, GRB2 was increased at $48 \mathrm{~h}$ treatment but $\mathrm{p}$-FAK was increased at $48 \mathrm{~h}$ treatment of PEITC (Fig. 5C). However, for BITC treatment only GRB2 at $24 \mathrm{~h}$ treatment was increased and p-FAK, RhoA, Ras and SOS-1 were decreased at 24 and $48 \mathrm{~h}$ treatment including GRB2 at $48 \mathrm{~h}$ treatment of BITC (Fig. 5C). The MMP-2, MMP-9, uPA and TIMP were reduced at 24 and $48 \mathrm{~h}$ treatment of PEITC (Fig. 5D), however, at BITC treatment for 24 and $48 \mathrm{~h}$, MMP- 2 and MMP-9 were reduced, the TIMP- 1 was reduced at $24 \mathrm{~h}$ treatment of BITC, uPA was increased at both time periods of treatment and TIMP- 1 was increased at $48 \mathrm{~h}$

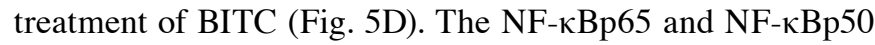
were reduced at 24 and $48 \mathrm{~h}$ treatment of PEITC, however, $\mathrm{BITC}$ at both treatment periods, NF- $\mathrm{\kappa Bp} 65$ were increased but NF- $\mathrm{\kappa Bp} 50$ was reduced at $48 \mathrm{~h}$ treatment but $24 \mathrm{~h}$ treatment was increased (Fig. 5E). The E-cadherin was increased at 24 and $48 \mathrm{~h}$ treatment of PEITC, however BITC treatment at both time periods were increased (Fig. 5F).
PEITC and BITC decreased the binding of NF- $\kappa$ Bp 65 on DNA in B16F10 cells. In order to understand the effects of PEITC and BITC on the binding of NF- $\mathrm{kBp} 65$ on DNA in B16F10 cells, cells were treated with $0,1,2.5$ and $5 \mu \mathrm{M}$ of PEITC and BITC for $48 \mathrm{~h}$ and were assayed by using EMSA. The results are shown in Fig. 6. The results indicated that NF- $\mathrm{kBp} 65$ bind on DNA was decreased in PEITC treatment, however, BITC treatment was increased.

\section{Discussion}

Numerous studies have shown that phenethyl isothiocyanate (PEITC) and benzyl isothiocyanate (BITC) significantly induced cytotoxic effects on many human cancer cell lines. The cytotoxic effects include decreased percentage of viable cell number through cell cycle arrest and apoptosis. However, currently how PEITC and BITC affect mouse melanoma B16F10 cell migration and invasion are unclear. Thus, in the present studies, we investigated PEITC and BITC effect on cell migration and invasion in $\mathrm{B} 16 \mathrm{~F} 10$ cells in vitro and we found that 1) PEITC has lower cytotoxic effects than that of BITC (Fig. 1), thus, we selected 1, 2.5 and $5 \mu \mathrm{M}$ for further experiments; 2) wound healing assay showed that PEITC have lower inhibition of wound healing (mobility) than that of BITC except at high dose $(5 \mu \mathrm{M})$ PEITC inhibited cell mobility more than that of BITC (Fig. 2); 3) results obtained from Transwell chamber coated with collagen or matrigel for cell migration and invasion, respectively, PEITC inhibited cell migration more than that of BITC (Fig. 3A) and PEITC inhibited cell invasion more than that of BITC (Fig. 3B); 4) the inhibition of MMP-2 activity was not significantly different between PEITC and BITC (Fig. 4) western blot examination demonstrated that PEITC has reduced MAPK signaling-associated proteins such as p-ERK1/2, p-p38 and p-JNK1/2 (Fig. 5A), but BITC 
treatment increased all those MAPK signaling associated proteins (Fig. 5A).

The PEITC increased PI3K but BITC decreased PI3K at both time periods of treatment (Fig. 5B). PEITC and BITC both suppressed the expression of RhoA, Ras, and SOS-1, however, PEITC increased FAK and GRB2, but BITC increased FAK at $48 \mathrm{~h}$ (Fig. 5C). PEITC decreased the expression of matrix metalloproteinase-2 (MMP-2) and tissue inhibitors of matrix metalloproteinase-1 (TIMP-1) but BITC increased them (Fig. 5D). At $48 \mathrm{~h}$ treatment, PEITC decreased NF- $\kappa$ Bp65 and NF- $\kappa$ Bp50 but BITC increased both (Fig. 5E) and both increased E-cadherin (Fig. 5F); 5) EMSA also confirmed that PEITC inhibited NF $-\kappa \mathrm{B}$ binding DNA but BITC increased $\mathrm{NF}-\kappa \mathrm{B}$ binding to DNA in B16F10 cells (Fig. 6). All these observations are compatible with PEITC and BITC have antimetastasis capabilities. Thus, our findings may prove that PEITC and BITC have potential as anti-metastatic in melanoma.

It is well known that approximately $90 \%$ of cancer deaths are caused by metastasis but the exact pathogenesis and mechanisms involved are not completely clear (34). Herein, we used wound healing and Transwell filter to show B16F10 cell suppression of the cell migration and invasion (Figs. 2 and 3). It is well documented that matrix metalloproteinases (MMPs) are involved in cell metastasis (24) and inhibition of MMPs can lead to suppression of cancer cell metastasis (35). Thus, one of the strategies for inhibiting cancer metastasis is to suppress the regulation of MMP proteins. Increased MMP-2 and MMP-9 activities and expression levels are correlated with reduced survival and poor prognosis in human malignancies $(36,37)$ and in many pathological processes including metastatic cancer and tumor-induced angiogenesis (38). In the present study, we used gelatin zymography assay which demonstrated that PEITC and BITC inhibited activities of MMP-2 in B16F10 cells (Fig. 4). PEITC and BITC inhibited MMP-2 production (Fig. 5D) and activity (Fig. 4) is also evident from the inhibition of collagen matrix invasion in B16F10 cells in vitro. MMP-2 (gelatinases) involved in tumor invasion and angiogenesis and chemical suppression of MMP-2 may lead to the inhibition of tumor metastasis $(39,40)$. Results from western blotting indicated that PEITC and BITC at 24 and $48 \mathrm{~h}$ treatment significantly reduced the protein levels of MMP-2 (Fig. 5D) and PEITC inhibited TIMP-1 at 24 and $48 \mathrm{~h}$ treatment but BITC at $48 \mathrm{~h}$ treatment led to increased TIMP-1 (Fig. 5D). PEITC suppressed urokinase-type plasminogen activator (uPA) at 24 and $48 \mathrm{~h}$ treatment but BITC increased it at both treatment times (Fig. 5D). The uPA protein expression levels have also been considered as promising targets of anticancer drugs (41) because it is involved in cell invasion and metastasis. It was reported that uPA gene transcription is involved in motifs that upstream sequences which correspond to NF- $\mathrm{BB}, \mathrm{AP}-1$, and PEA3-binding sites $(42,43)$.

In the current study, the effects of PEITC and BITC on $\mathrm{NF}-\kappa \mathrm{B}$ transcription activity (DNA binding) were examined by using EMSA assay and results (Fig. 6) indicated that PEIT reduce the binding of $\mathrm{NF}-\kappa \mathrm{B}$ to DNA in DNA-binding domains but BITC elevated the binding of NF- $\kappa$ B to DNA in DNA-binding domains (Fig. 6). Based on the results from western blotting indicated that PEITC suppressed the expression of MMP-2 and TIMP-1 but BITC increased them (Fig. 5D) and TIMPs act as natural inhibitors of MMPs by tightly binding the MMP in a 1:1 stoichiometric ratio (44).

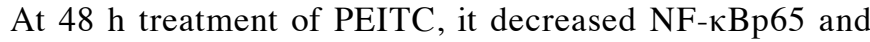
NF- $\kappa$ Bp50 but BITC increased both (Fig. 5E) and both increased E-cadherin (Fig. 5F). This reduced binding activity was accompanied by inhibition of the nuclear protein expression of this factor in B16F10 cells that was confirmed by western blotting. These results indicated that NF- $\kappa \mathrm{B}$ binding activity suppression was also possibly implicated in the inhibition of MMP or uPA synthesis. It is well known that cancer cells can express high levels of MMPs, cathepsins and uPA, which degrade tissue extracellular matrix (ECM) and facilitate cancer invasion and metastasis (45). NF- $\kappa \mathrm{B}$ is a complex family, thus, further investigations are needed in the future. These MMPs have been shown to be present in different types of cancer cells, including melanoma, lung and breast (46).

Numerous studies have shown that in many physiological and pathological settings, the mitogen-activated protein kinase (MAPK) pathway involved in regulating cell death and survival $(47,48)$ plays a central role in regulating the expression of MMP-2 and MMP-9 (49). MMPs are partly mediated by the MAPK pathway $(50,51)$. MAPK includes ERK1/2, c-Jun NH2-terminal kinase, and p38 and other factors. The MAPK pathway regulated various cellular activities such as proliferation, invasion, metastasis, and death (52). It was suggested that agents to inhibit the MAPK pathway might lead to prevent cancer angiogenesis, proliferation, invasion, and metastasis including melanoma $(49,53)$. Results from western blotting indicated that PEITC and BITC treatment at 24 and $48 \mathrm{~h}$ significantly reduced the expression of p-ERK1/2, p-p38 and p-JNK1/2 when compared to control (Fig. 5A) which means PEITC and BITC suppressed MAPK signal pathway in B16F10 cells. Fig. 5B indicated that p-AKT(Thr308), p-AKT(Ser473) and PCAN were reduced in PEITC and BITC treatment, however, both agents increased AKT expression in B16F10 cells. Activated PI3K and its downstream target Akt have been recognized to be involved with tumor cell invasion, and oncogenesis $(54,55)$. The downregulation of the PI3k/Akt pathway have been reported to decrease the invasion of melanoma cells $(53,56)$. In melanoma cells, the activation of the PI3K-Akt signaling pathway promoting cell invasion has been shown (57). AKT, downstream of PI3K has been reported to be suppressed by the transcription of the E-cadherin gene (58). Ras regulating RhoA has been recognized to affect tumor cells transmigration through mesothelial monolayer (59). Results (Fig. 5C) indicated that PEITC and BITC significantly reduced the expression of RhoA and Ras in B16F10 cells at both treatment times. Thus, PEITC and BITC inhibited B16F10 cell migration and invasion may also be via the inhibition of RhoA and Ras.

In conclusion, our results indicated that PEITC and BITC reduced the viable cell number of B16F10 cells. We selected the low concentrations $(1,2.5$ and $5 \mu \mathrm{M})$ of PEITC and BITC bufalin for examining the effects of cancer cell metastasis and we found that PEITC and BITC significantly inhibited cell mobility, migration and invasion of B16F10 cells in vitro. We also used western blot assay and found that PEITC and BITC inhibited many metastasis-associated protein molecules including MMP-2, MAPKs, E-cadherin, Ras, RhoA and $N F-\kappa B$. NF- $\kappa$ B also was confirmed by confocal laser microscopy examination. This finding suggests that PEITC and BITC 
are potential candidates for the development of chemotherapeutic treatments for melanoma cells in the future.

\section{Acknowledgements}

The present study was supported by grants NSC1032320-B-039-037 from the National Science Council, Taipei, Taiwan.

\section{References}

1. Soengas MS and Lowe SW: Apoptosis and melanoma chemoresistance. Oncogene 22: 3138-3151, 2003.

2. Hersey P, Zhuang L and Zhang XD: Current strategies in overcoming resistance of cancer cells to apoptosis melanoma as a model. Int Rev Cytol 251: 131-158, 2006.

3. Sykes EK, Mactier S and Christopherson RI: Melanoma and the Unfolded Protein Response. Cancers (Basel) 8: 8, 2016.

4. Sharma A, Shah SR, Illum H and Dowell J: Vemurafenib: Targeted inhibition of mutated BRAF for treatment of advanced melanoma and its potential in other malignancies. Drugs 72: 2207-2222, 2012.

5. Xiao D, Johnson CS, Trump DL and Singh SV: Proteasomemediated degradation of cell division cycle $25 \mathrm{C}$ and cyclin-dependent kinase 1 in phenethyl isothiocyanate-induced G2-M-phase cell cycle arrest in PC-3 human prostate cancer cells. Mol Cancer Ther 3: 567-575, 2004.

6. Yeh YT, Yeh H, Su SH, Lin JS, Lee KJ, Shyu HW, Chen ZF, Huang SY and Su SJ: Phenethyl isothiocyanate induces DNA damage-associated G2/M arrest and subsequent apoptosis in oral cancer cells with varying p53 mutations. Free Radic Biol Med 74: 1-13, 2014.

7. Øverby A, Zhao CM, Bones AM and Chen D: Naturally occurring phenethyl isothiocyanate-induced inhibition of gastric cancer cell growth by disruption of microtubules. J Gastroenterol Hepatol 29 (Suppl 4): 99-106, 2014.

8. Chou YC, Chang MY, Wang MJ, Liu HC, Chang SJ, Harnod T, Hung $\mathrm{CH}$, Lee HT, Shen CC and Chung JG: Phenethyl isothiocyanate alters the gene expression and the levels of protein associated with cell cycle regulation in human glioblastoma GBM 8401 cells. Environ Toxicol 32: 176-187, 2017.

9. Huong D, Shim JH, Choi KH, Shin JA, Choi ES, Kim HS, Lee SJ, Kim SJ, Cho NP and Cho SD: Effect of $\beta$-phenylethyl isothiocyanate from cruciferous vegetables on growth inhibition and apoptosis of cervical cancer cells through the induction of death receptors 4 and 5. J Agric Food Chem 59: 8124-8131, 2011.

10. Hwang ES and Lee HJ: Effects of phenylethyl isothiocyanate and its metabolite on cell-cycle arrest and apoptosis in LNCaP human prostate cancer cells. Int J Food Sci Nutr 61: 324-336, 2010.

11. Yan H, Zhu Y, Liu B, Wu H, Li Y, Wu X, Zhou Q and Xu K: Mitogen-activated protein kinase mediates the apoptosis of highly metastatic human non-small cell lung cancer cells induced by isothiocyanates. Br J Nutr 106: 1779-1791, 2011.

12. Xu C, Shen G, Chen C, Gélinas C and Kong AN: Suppression of NF-kappaB and NF-kappaB-regulated gene expression by sulforaphane and PEITC through IkappaBalpha, IKK pathway in human prostate cancer PC-3 cells. Oncogene 24: 4486-4495, 2005.

13. Bommareddy A, Hahm ER, Xiao D, Powolny AA, Fisher AL, Jiang Y and Singh SV: Atg5 regulates phenethyl isothiocyanateinduced autophagic and apoptotic cell death in human prostate cancer cells. Cancer Res 69: 3704-3712, 2009.

14. Kelloff GJ, Crowell JA, Hawk ET, Steele VE, Lubet RA, Boone CW, Covey JM, Doody LA, Omenn GS, Greenwald P, et al: Strategy and planning for chemopreventive drug development: Clinical development plans II. J Cell Biochem (Suppl 26): 54-71, 1996.

15. Chen HJ, Lin CM, Lee CY, Shih NC, Amagaya S, Lin YC and Yang JS: Phenethyl isothiocyanate suppresses EGF-stimulated SAS human oral squamous carcinoma cell invasion by targeting EGF receptor signaling. Int J Oncol 43: 629-637, 2013.

16. Tang $\mathrm{L}$ and Zhang Y: Dietary isothiocyanates inhibit the growth of human bladder carcinoma cells. J Nutr 134: 2004-2010, 2004

17. Xiao D, Powolny AA and Singh SV: Benzyl isothiocyanate targets mitochondrial respiratory chain to trigger reactive oxygen species-dependent apoptosis in human breast cancer cells. J Biol Chem 283: 30151-30163, 2008
18. Batra S, Sahu RP, Kandala PK and Srivastava SK: Benzyl isothiocyanate-mediated inhibition of histone deacetylase leads to NF-kappaB turnoff in human pancreatic carcinoma cells. Mol Cancer Ther 9: 1596-1608, 2010.

19. Liu KC, Huang YT, Wu PP, Ji BC, Yang JS, Yang JL, Chiu TH, Chueh FS and Chung JG: The roles of AIF and Endo G in the apoptotic effects of benzyl isothiocyanate on DU 145 human prostate cancer cells via the mitochondrial signaling pathway. Int J Oncol 38: 787-796, 2011.

20. Huang SH, Wu LW, Huang AC, Yu CC, Lien JC, Huang YP, Yang JS, Yang JH, Hsiao YP, Wood WG, et al: Benzyl isothiocyanate (BITC) induces $\mathrm{G} 2 / \mathrm{M}$ phase arrest and apoptosis in human melanoma A375.S2 cells through reactive oxygen species (ROS) and both mitochondria-dependent and death receptormediated multiple signaling pathways. J Agric Food Chem 60: 665-675, 2012.

21. Zhou T, Li G, Cao B, Liu L, Cheng Q, Kong H, Shan C, Huang X, Chen J and Gao N: Downregulation of Mcl-1 through inhibition of translation contributes to benzyl isothiocyanate-induced cell cycle arrest and apoptosis in human leukemia cells. Cell Death Dis 4: e515, 2013.

22. Tang NY, Chueh FS, Yu CC, Liao CL, Lin JJ, Hsia TC, Wu KC, Liu HC, Lu KW and Chung JG: Benzyl isothiocyanate alters the gene expression with cell cycle regulation and cell death in human brain glioblastoma GBM 8401 cells. Oncol Rep 35: 2089-2096, 2016.

23. Chambers AF, Groom AC and MacDonald IC: Dissemination and growth of cancer cells in metastatic sites. Nat Rev Cancer 2: 563-572, 2002

24. Cruz-Munoz W and Khokha R: The role of tissue inhibitors of metalloproteinases in tumorigenesis and metastasis. Crit Rev Clin Lab Sci 45: 291-338, 2008.

25. Lee CS, Cho HJ, Jeong YJ, Shin JM, Park KK, Park YY, Bae YS, Chung IK, Kim M, Kim CH, et al: Isothiocyanates inhibit the invasion and migration of C6 glioma cells by blocking FAK/JNK-mediated MMP-9 expression. Oncol Rep 34: 2901-2908, 2015.

26. Wu X, Zhu Y, Yan H, Liu B, Li Y, Zhou Q and Xu K: Isothiocyanates induce oxidative stress and suppress the metastasis potential of human non-small cell lung cancer cells. BMC Cancer 10: 269, 2010.

27. Shih YL, Chou J, Yeh MY, Chou HM, Chou HC, Lu HF, Shang HS, Chueh FS, Chu YL, Hsueh SC, et al: Casticin induces DNA damage and inhibits DNA repair-associated protein expression in B16F10 mouse melanoma cancer cells. Oncol Rep 36: 2094-2100, 2016

28. Chen YY, Lu HF, Hsu SC, Kuo CL, Chang SJ, Lin JJ, Wu PP, Liu JY, Lee $\mathrm{CH}$, Chung JG, et al: Bufalin inhibits migration and invasion in human hepatocellular carcinoma SK-Hepl cells through the inhibitions of NF- $\kappa \mathrm{B}$ and matrix metalloproteinase2/-9-signaling pathways. Environ Toxicol 30: 74-82, 2015.

29. Huang YP and Chang NW: PPAR $\alpha$ modulates gene expression profiles of mitochondrial energy metabolism in oral tumorigenesis. Biomedicine (Taipei) 6: 3, 2016.

30. Huang AC, Yang MD, Hsiao YT, Lin TS, Ma YS, Peng SF, Hsia TC, Cheng YD, Kuo CL and Chung JG: Bufalin inhibits gefitinib resistant NCI-H460 human lung cancer cell migration and invasion in vitro. J Ethnopharmacol 194: 1043-1050, 2016.

31. Chan CY, Lien CH, Lee MF and Huang CY: Quercetin suppresses cellular migration and invasion in human head and neck squamous cell carcinoma (HNSCC). Biomedicine (Taipei) 6: 15, 2016.

32. Lin M-C, Tsai S-Y, Wang F-Y, Liu F-H, Syu J-N and Tang F-Y: Leptin induces cell invasion and the upregulation of matrilysin in human colon cancer cells. BioMedicine 3: 174-180, 2013. http://biomedicine.cmu.edu.tw/doc/9-5.pdf.

33. Kuo TC, Yang JS, Lin MW, Hsu SC, Lin JJ, Lin HJ, Hsia TC, Liao CL, Yang MD, Fan MJ, et al: Emodin has cytotoxic and protective effects in rat C6 glioma cells: Roles of Mdrla and nuclear factor kappaB in cell survival. J Pharmacol Exp Ther 330: 736-744, 2009.

34. Wu Y and Zhou BP: New insights of epithelial-mesenchymal transition in cancer metastasis. Acta Biochim Biophys Sin (Shanghai) 40: 643-650, 2008.

35. Jia W, Gao XJ, Zhang ZD, Yang ZX and Zhang G: S100A4 silencing suppresses proliferation, angiogenesis and invasion of thyroid cancer cells through downregulation of MMP-9 and VEGF. Eur Rev Med Pharmacol Sci 17: 1495-1508, 2013. 
36. Kallakury BV, Karikehalli S, Haholu A, Sheehan CE, Azumi N and Ross JS: Increased expression of matrix metalloproteinases 2 and 9 and tissue inhibitors of metalloproteinases 1 and 2 correlate with poor prognostic variables in renal cell carcinoma. Clin Cancer Res 7: 3113-3119, 2001.

37. Yoshizaki T, Maruyama Y, Sato H and Furukawa M: Expression of tissue inhibitor of matrix metalloproteinase- 2 correlates with activation of matrix metalloproteinase- 2 and predicts poor prognosis in tongue squamous cell carcinoma. Int J Cancer 95: 44-50, 2001.

38. Hsieh YS, Chu SC, Hsu LS, Chen KS, Lai MT, Yeh CH and Chen PN: Rubus idaeus L. reverses epithelial-to-mesenchymal transition and suppresses cell invasion and protease activities by targeting ERK1/2 and FAK pathways in human lung cancer cells. Food Chem Toxicol 62: 908-918, 2013.

39. Li D, Qu X, Hou K, Zhang Y, Dong Q, Teng Y, Zhang J and Liu Y: PI3K/Akt is involved in bufalin-induced apoptosis in gastric cancer cells. Anticancer Drugs 20: 59-64, 2009.

40. Rajoria S, Suriano R, George A, Shanmugam A, Schantz SP Geliebter J and Tiwari RK: Estrogen induced metastatic modulators MMP-2 and MMP-9 are targets of 3,3'-diindolylmethane in thyroid cancer. PLoS One 6: e15879, 2011.

41. Chu SC, Yu CC, Hsu LS, Chen KS, Su MY and Chen PN: Berberine reverses epithelial-to-mesenchymal transition and inhibits metastasis and tumor-induced angiogenesis in human cervical cancer cells. Mol Pharmacol 86: 609-623, 2014.

42. D'Orazio D, Besser D, Marksitzer R, Kunz C, Hume DA, Kiefer B and Nagamine Y: Cooperation of two PEA3/AP1 sites in uPA gene induction by TPA and FGF-2. Gene 201: 179-187, 1997.

43. Mori Y, Akita K, Tanida S, Ishida A, Toda M, Inoue M, Yashiro M, Sawada T, Hirakawa K and Nakada H: MUC1 protein induces urokinase-type plasminogen activator (uPA) by forming a complex with NF-kB p65 transcription factor and binding to the uPA promoter, leading to enhanced invasiveness of cancer cells. J Biol Chem 289: 35193-35204, 2014

44. Offenberg H, Brünner N, Mansilla F, Orntoft Torben F and Birkenkamp-Demtroder K: TIMP-1 expression in human colorectal cancer is associated with TGF-B1, LOXL2, INHBA1, TNF-AIP6 and TIMP-2 transcript profiles. Mol Oncol 2: 233-240, 2008

45. Pulyaeva H, Bueno J, Polette M, Birembaut P, Sato H, Seiki M and Thompson EW: MT1-MMP correlates with MMP-2 activation potential seen after epithelial to mesenchymal transition in human breast carcinoma cells. Clin Exp Metastasis 15: 111-120, 1997.

46. Heppner KJ, Matrisian LM, Jensen RA and Rodgers WH: Expression of most matrix metalloproteinase family members in breast cancer represents a tumor-induced host response. Am J Pathol 149: 273-282, 1996.

47. Eisenmann KM, VanBrocklin MW, Staffend NA, Kitchen SM and Koo HM: Mitogen-activated protein kinase pathwaydependent tumor-specific survival signaling in melanoma cells through inactivation of the proapoptotic protein bad. Cancer Res 63: 8330-8337, 2003.
48. Junttila MR, Li SP and Westermarck J: Phosphatase-mediated crosstalk between MAPK signaling pathways in the regulation of cell survival. FASEB J 22: 954-965, 2008.

49. Lee KR, Lee JS, Kim YR, Song IG and Hong EK: Polysaccharide from Inonotus obliquus inhibits migration and invasion in B16-F10 cells by suppressing MMP-2 and MMP-9 via downregulation of NF- $\mathrm{BB}$ signaling pathway. Oncol Rep 31: 2447-2453, 2014.

50. Mori T, Wang X, Aoki T and Lo EH: Downregulation of matrix metalloproteinase-9 and attenuation of edema via inhibition of ERK mitogen activated protein kinase in traumatic brain injury. J Neurotrauma 19: 1411-1419, 2002.

51. Shin DY, Lu JN, Kim GY, Jung JM, Kang HS, Lee WS and Choi YH: Anti-invasive activities of anthocyanins through modulation of tight junctions and suppression of matrix metalloproteinase activities in HCT-116 human colon carcinoma cells. Oncol Rep 25: 567-572, 2011.

52. Sun Y, Liu WZ, Liu T, Feng X, Yang N and Zhou HF: Signaling pathway of MAPK/ERK in cell proliferation, differentiation, migration, senescence and apoptosis. J Recept Signal Transduct Res 35: 600-604, 2015.

53. Lin BW, Jiao ZL, Fan JF, Peng L, Li L, Zhao ZG, Ding XY and $\mathrm{Li} \mathrm{HJ}$ : Inhibitory effect of melanoma differentiation associated gene-7/interleukin-24 on invasion in vitro of human melanoma cancer cells. J Korean Med Sci 28: 833-839, 2013.

54. Kim D, Kim S, Koh H, Yoon SO, Chung AS, Cho KS and Chung J: Akt/PKB promotes cancer cell invasion via increased motility and metalloproteinase production. FASEB J 15: 1953-1962, 2001.

55. Shukla S, Maclennan GT, Hartman DJ, Fu P, Resnick MI and Gupta S: Activation of PI3K-Akt signaling pathway promotes prostate cancer cell invasion. Int J Cancer 121: 1424-1432, 2007.

56. Shi H, Wu Y, Wang Y, Zhou M, Yan S, Chen Z, Gu D and Cai Y: Liquiritigenin potentiates the inhibitory effects of cisplatin on invasion and metastasis via downregulation MMP-2/9 and PI3K/AKT signaling pathway in B16F10 melanoma cells and mice model. Nutr Cancer 67: 761-770, 2015.

57. Thang ND, Yajima I, Kumasaka MY, Iida M, Suzuki T and Kato M: Deltex-3-like (DTX3L) stimulates metastasis of melanoma through FAK/PI3K/AKT but not MEK/ERK pathway. Oncotarget 6: 14290-14299, 2015.

58. Qiao M, Sheng S and Pardee AB: Metastasis and AKT activation. Cell Cycle 7: 2991-2996, 2008.

59. Narumiya $\mathrm{S}$, Tanji $\mathrm{M}$ and Ishizaki $\mathrm{T}$ : Rho signaling, ROCK and $\mathrm{mDia}$, in transformation, metastasis and invasion. Cancer Metastasis Rev 28: 65-76, 2009. 